\title{
Platformsturing van zelforganisatie tijdens rampen
}

\author{
Kees Boersma, Julie Ferguson, Peter Groenewegen, Femke Mulder, Arjen Schmidt \& \\ Jeroen Wolbers
}

\begin{abstract}
Tijdens een ramp of crisis komt de responsecapaciteit van het openbaar bestuur extreem onder druk te staan. Daarentegen zijn burgers in tijden van crisis veerkrachtig en weten ze zichzelf steeds beter te organiseren. De mogelijkheden van sociale media en online platforms hebben door verbeterde connectiviteit de mogelijkheden voor zelforganisatie alleen maar versterkt. In de praktijk zien we dat overheden het lastig vinden om met deze vorm van zelforganisatie om te gaan, terwijl dit ook een unieke mogelijkheid is om meer responsecapaciteit te benutten. Het slim benutten van de burgerinitiatieven biedt kansen en kan de slagkracht van het overheidsoptreden vergroten. In dit artikel staat de volgende vraag centraal: welke rol spelen online platforms bij het slim sturing geven aan zelforganisatie van burgers tijdens crises en rampen? We beantwoorden de vraag aan de hand van twee voorbeelden: de rol van online platforms in de nasleep van de aardbevingen in Nepal in 2015 en bij de coördinatie van de opvang van vluchtelingen tijdens de crisis in Nederland in de winter van 2015-2016.
\end{abstract}

\section{Burgerinitiatieven tijdens crises en rampen}

Tijdens een crisis of ramp staat de overheidscapaciteit extreem onder druk. De rol van de overheid is om de effecten van de ramp te verkleinen en haar burgers zo goed mogelijk te beschermen. Dat is een lastige taak, want de situatie na een

* Kees Boersma, PhD is universitair hoofddocent bij de Afdeling Organisatiewetenschappen van de Faculteit der Sociale Wetenschappen van de Vrije Universiteit Amsterdam, expert op het gebied van crisismanagement en rampenbestrijding, en leider van het NWO Smart Disaster Governance-project. Julie Ferguson, $\mathrm{PhD}$, is universitair docent bij de Afdeling Organisatiewetenschappen van de Faculteit der Sociale Wetenschappen van de Vrije Universiteit Amsterdam en expert op het gebied van humanitaire hulpverlening en kennisnetwerken. Peter Groenewegen, $\mathrm{PhD}$ is hoogleraar bij de Afdeling Organisatiewetenschappen van de Faculteit der Sociale Wetenschappen van de Vrije Universiteit Amsterdam, gespecialiseerd in organisatietheorie en sociale netwerken. Femke Mulder, MSc is promovendus bij de Afdeling Organisatiewetenschappen van de Faculteit der Sociale Wetenschappen van de Vrije Universiteit Amsterdam binnen het NWO Smart Governance-project, waarin ze zich richt op de netwerken van de internationale humanitaire hulpverlening. Arjen Schmidt, MSc is promovendus bij de Afdeling Organisatiewetenschappen van de Faculteit der Sociale Wetenschappen van de Vrije Universiteit Amsterdam binnen het NWO Smart Governance-project, waarin hij zich richt op de governance van rampenbestrijding in Nederland. Jeroen Wolbers, $\mathrm{PhD}$ is postdoc bij de Afdeling Organisatiewetenschappen van de Faculteit der Sociale Wetenschappen van de Vrije Universiteit Amsterdam binnen het NWO Smart Governance-project, waarin hij zich richt op de adaptieve capaciteit van (overheids)organisaties in de rampenbestrijding. 
ramp is chaotisch en kenmerkt zich door complexiteit en onzekerheid. In de media krijgen ontstane paniek en sociale onrust heel veel aandacht. Om zo adequaat mogelijk op te treden in de nasleep van een ramp probeert de overheid controle over de situatie te krijgen (Tierney, 2014). De response in reactie op deze bedreigingen wordt dan ook vaak gekenmerkt door een top-downaanpak en acties gericht op de handhaving van de veiligheid en openbare orde. De naam crisisbeheersing is in dat kader veelzeggend.

Het ligt voor de hand dat de overheid zich richt op de wanorde na een ramp; bescherming van haar burgers is immers een belangrijke overheidstaak. Echter, de uitkomsten van wetenschappelijk onderzoek naar rampen en crises laten zien dat het beeld van maatschappelijke wanorde en onrust heel eenzijdig is. Paniek en ongewenst gedrag van burgers zijn eerder uitzondering dan regel. Sterker nog, het zijn de burgers, en niet de overheidsorganisaties, die als eerste ter plekke zijn om hulp te verlenen (Helsloot \& Ruitenberg, 2004). In de nasleep van rampen handelen burgers veelal altruïstisch en verlenen ze elkaar spontaan hulp. Rampen verbinden getroffenen en brengen niet zelden gemeenschapszin (terug) in de samenleving (Solnit, 2010). Zo waren burgers na de aanslagen van 9/11 in staat om een grootschalige evacuatie over water uit te voeren (Kendra \& Wachtendorf, 2016). In de nasleep van de Queensland Floods in Australië stonden tegen de verwachting in files de stad in, in plaats van de stad uit. Burgers kwamen massaal helpen met het opruimen van het puin en de modder (Bunce, Partridge \& Davis, 2012). In Nederland zien we ook dat burgers spontane initiatieven op touw zetten in reactie op een crisissituatie. De toestroom van vluchtelingen naar Nederland in de winter van 2015-2016 veroorzaakte een situatie van onrust en onzekerheid. De overheidsinstanties die verantwoordelijk waren voor de opvang, met name het Centraal Orgaan opvang Asielzoekers (COA), bleken niet over voldoende capaciteit en flexibiliteit te beschikken om vluchtelingen en statushouders adequaat op te vangen (Smets, Younes, Dohmen, Boersma \& Brouwer, 2017). Lokale burgerinitiatieven in grote steden, zoals in Amsterdam, namen het voortouw door statushouders op kleine schaal te huisvesten in buurtgemeenschappen (Boersma, Kraiukhina, Larruina, Lehota \& Nury, 2018).

De aandacht voor burgerinitiatieven tijdens rampen is niet nieuw. Al sinds de jaren zestig is goed gedocumenteerd dat burgers in staat zijn om zichzelf te organiseren na een ramp (Dynes, 1994). Wat nieuw is, zijn de toegenomen mogelijkheden voor het slim toepassen van sturingsmechanismen door de opkomst van nieuwe communicatietechnologie, zoals sociale media en web 2.0 platforms zoals Facebook en Twitter (Meijer, 2011; Slot, Cuppen, Doorn, Galeano Galvan \& Klievink, 2017). Dergelijke online platforms bieden de mogelijkheid aan geïnteresseerden om contacten te leggen, informatie te delen en om zichzelf te organiseren. In de nasleep van een ramp of crisis gebruiken burgers deze platforms om zich te mobiliseren, informatie uit te wisselen en aansluiting te vinden bij verschillende initiatieven (Albris, 2018). Bijvoorbeeld, na de aanslagen in Parijs op 13 november 2015 organiseerden burgers binnen een half uur een ad-hoc-noodopvang via 
Twitter door zelf schuilplaatsen aan te bieden via de hashtag \#PorteOuverte (open deur) (Ross, 2015).

De laatste jaren is er ook in de bestuurskunde veel aandacht besteed aan vormen van zelforganisatie en coproductie, al dan niet via online platforms, waarbij overheidsorganisaties samenwerken met relevante stakeholders, inclusief burgerinitiatieven (Voorberg, Bekkers \& Tummers, 2015). Eigenaarschap en betrokkenheid spelen daarbij een grote rol, evenals vraagstukken van legitimiteit en betrouwbaarheid. Daarbij komt nog dat overheden te maken hebben met beperkte capaciteit om adequaat te reageren op de ontstane situatie. De behoefte tot sturing en bijsturing blijft bestaan omdat de uitkomsten van burgerinitiatieven en coproductie onzeker zijn. Wat zelforganisatie tijdens en na een crisis nog extra ingewikkeld maakt, is de grote tijdsdruk waaronder het plaatsvindt. Bovendien komt een crisis onverwacht en is het lastig in te schatten wie de relevante stakeholders zijn. Met andere woorden: een crisis en de maatschappelijke gevolgen daarvan dagen bestaande en zelfs de meest vernieuwende governance-structuren uit. In dit artikel bekijken we de aard en potentie van platformsturing tijdens crisis en rampen: het benutten en aansturen van de organisatiekracht van decentrale (online) initiatieven (Janssen \& Estevez, 2013). Mede door de invloed van nieuwe technologie en communicatiemogelijkheden zijn de aard en structuur van de onderlinge relaties van stakeholders veranderd van homogeen naar divers en van statisch naar dynamisch. Nieuwe ad hoc en flexibelere organisatievormen zijn mogelijk geworden als alternatief voor traditionele hiërarchische hulpverleningsstructuren.

\section{Aanpak}

Het openbaar bestuur worstelt om met nieuwe web 2.0-initiatieven om te gaan in de huidige sturingsarrangementen (Meijer, Koops, Pieterson, Overman \& Tije, 2012). Vragen als wie is er verantwoordelijk en voor wat precies, welk mandaat hebben verschillende stakeholders, en wie heeft eigenaarschap over wat, spelen een belangrijke rol. In het geval van crisismanagement ligt de bestuurlijke uitdaging niet in beheersing, maar in het leren vertrouwen op en overlaten aan de kracht van initiatieven die burgers tijdens een crisis spontaan en op eigen initiatief initiëren (Boersma, Ferguson, Groenewegen \& Wolbers, 2014). Voortbouwend op ons onderzoek ${ }^{1}$ naar burgerinitiatieven en de rol van online platforms tijdens crises en rampen staat in dit artikel de volgende vraag centraal: welke rol spelen online platforms bij het slim sturing geven aan zelforganisatie van burgers tijdens crises en rampen? Voor de beantwoording van deze vraag hebben we allereerst gegevens verzameld rondom de opkomst van online platforms bij internationale humanitaire hulpverlening, en met name tijdens de hulpverlening na de aardbe-

1 Het onderzoek in Nepal en Nederland maakt deel uit van het NWO 'Smart Disaster Governance'project. Het project richt zich op de samenwerking tussen hulpdiensten onderling en tussen hulpdiensten en burgers tijdens crisissituaties en rampen in de Nederlandse en internationale humanitaire context. 
vingen in Nepal in 2015. In de tweede plaats hebben we de rol van een online platform bestudeerd in Nederland in de winter van 2015-2016, waarin de toestroom van vluchtelingen uitmondde in een crisissituatie. In beide gevallen hebben we gesproken met sleutelinformanten, initiatiefnemers, overheidsfunctionarissen en vrijwilligers (Mulder, Ferguson, Groenewegen, Boersma \& Wolbers, 2016; Wolbers, Ferguson, Groenewegen, Mulder \& Boersma, 2016; Schmidt, Wolbers, Ferguson \& Boersma, 2017). We hebben onze interviews gecombineerd met impressies opgedaan tijdens veldwerk, en hebben daarnaast een studie gedaan naar de betrokken stakeholders en hun netwerken.

\section{Online platforms}

Ons onderzoek in Nepal en Nederland bevestigt allereerst het beeld dat burgers bijzonder actief zijn tijdens rampsituaties en crisis, veelal in positieve zin, als vrijwilligers. Zowel in Nepal als in Nederland bleken burgers uitstekend in staat zich te mobiliseren, initiatieven te ondernemen en nieuwe organisatievormen te ontwikkelen. Tegelijkertijd werd zichtbaar dat overheidsinstanties moeite hadden aan te haken bij deze spontane gemeenschapsinitiatieven. De overheidsorganisaties verantwoordelijk voor de rampenbestrijding zijn ingericht en georganiseerd via formele, bureaucratische lijnen waarbij legitimiteit en verantwoording van handelen een grote rol spelen. De acties van burgers via platforms die we hebben onderzocht daarentegen waren over het algemeen spontaan georganiseerd, zonder formele spelregels of afgebakende verantwoordelijkheden.

In Nepal zagen we de invloedrijke rol van een online platform: QuakeMap (Mulder, F., Ferguson, Groenewegen, Boersma \& Wolbers, 2016). Dit platform was geïnspireerd op een van de meest aansprekende vormen van platformsturing die opkwam in de nasleep van de aardbeving in Haïti in 2010. Een groep computerwetenschappers in Harvard ontwikkelde direct na de ramp via OpenStreetMaps online kaarten om het getroffen gebied en de hulpvragen in kaart te brengen (Mulder et al., 2016). Vier dagen na de aardbeving in Haïti openden vrijwilligers een gratis telefoonnummer (4636) waar sms-berichten met informatie over de ramp naartoe konden worden gestuurd. Via de Mission4636 werd informatie door middel van crowdsourcing geverifieerd en geplot. Deze vorm van crowdsourcing resulteerde in een van de meest actuele kaarten van het rampgebied (Zook, Graham, Shelton \& Gorman, 2010).

Deze zogenoemde crisismapping nam een wereldwijde vlucht en speelde ook in Nepal een belangrijke rol tijdens de hulpverlening (Streep, 2015). In de dagen dat de Nepalese overheid te kampen had met serieuze capaciteitsproblemen en de handen vol had met het inrichten van de eigen crisisorganisatie, richtten vrijwilligers in Nepal een ingenieus systeem in via Kathmandu Living Labs, een not-forprofit-organisatie, om informatie over de ramp op te halen en te delen. Het bouwde voort op initiatieven als OpenStreetMaps en Open Cities Kathmandu, deels ondersteund door de Wereldbank in Washington D.C. Naast het in kaart brengen van geografische gegevens organiseerden de initiatiefnemers van Open 
Cities Kathmandu mapping-workshops voor studenten en jeugdgroepen. Kathmandu Living Labs bleek een initiatief met een grote aantrekkingskracht voor lokale, veelal hoogopgeleide vrijwilligers, die actief werden in de eerste weken na de aardbevingen in Nepal in 2015.

Primair functioneerden de kaarten van Kathmandu Living Labs ter ondersteuning van hulpverlening aan getroffenen in de eerste dagen en weken na de ramp toen er weinig tot geen informatie beschikbaar was. Daarbij ging het om vragen rondom het schadebeeld, aantallen slachtoffers en de behoefte aan noodhulp. De lokale vraag naar hulpbehoefte in het getroffen gebied koppelden de vrijwilligers van Kathmandu Living Labs vervolgens aan het lokale aanbod door vrachtwagenchauffeurs te mobiliseren die hulpgoederen konden vervoeren. De door de maatschappelijke initiatieven gecreëerde kaarten bleken ook in de maanden na de ramp zo waardevol voor de rampenbestrijding, dat uiteindelijk ook de formele instanties gebruik begonnen te maken van de informatie voor bijvoorbeeld hun logistieke operatie. Daaronder zat het Nepalese leger, maar ook internationale humanitaire organisaties en de Verenigde Naties maakten er gebruik van. Crisismapping ondersteunde zo de coördinatie en coöperatie tussen de getroffenen en de te hulp schietende gemeenschappen. Dat laatste laat zien dat er voor overheden in crisissituaties ook nieuwe coalities te vormen zijn.

In Nederland is de opkomst van burgerinitiatieven via online platforms in de nasleep van rampen ook steeds beter zichtbaar. Tijdens ons onderzoek zagen we hoe het Rode Kruis via het door henzelf gestarte project Ready2Help experimenteerde met een online pool van burgervrijwilligers die ze konden oproepen om te assisteren bij een ramp of crisis (Schmidt, Wolbers, Ferguson \& Boersma, 2017). Via het Ready2Help-platform kunnen vrijwilligers zich aanmelden, zodat het Rode Kruis hen kan mobiliseren via een sms en hen kan inzetten om ondersteunende taken uit te voeren, zoals dijkversterking of logistieke ondersteuning om de formele rampenbestrijdingsorganisaties te ontlasten. Ready2Help intermedieert tussen spontane vrijwilligers en gevestigde hulporganisaties en is zo in staat de slagkracht van burgerinitiatieven te vergroten. Dit maakt Ready2Help tot een belangrijk nieuw sturingsmechanisme voor het organiseren van burgerhulpverlening. Het nut van deze vorm van platformsturing bleek tijdens de crisis bij de opvang van vluchtelingen (Boersma, Kraiukhina, Larruina, Lehota \& Nury, 2018). $\mathrm{Na}$ enige aarzeling verwelkomde het COA uiteindelijk de hulp van de Ready2Helpers bij de inrichting van nieuwe opvanglocaties. Het Rode Kruis speelde een belangrijke mediërende rol tussen de overheid en de spontane acties van de burgers. Dit initiatief gaf het Rode Kruis tevens de mogelijkheid om ervaring op te doen met andere vormen van vrijwilligerswerk.

\section{Nieuwe sturingsmogelijkheden: kansen en dilemma's}

Online platforms vormen dus een belangrijk nieuw middel om de burgerhulpverlening te organiseren en bieden nieuwe mogelijkheden voor mobilisatie van burgers. Uit ons onderzoek bleek bovenal dat platforms de kans bieden nieuwe orga- 
nisatieprincipes uit te proberen en toe te passen. Daarbij gaat het niet om de acties van permanente (overheids)organisaties, maar om tijdelijke arrangementen zonder veel hiërarchie en met een combinatie van netwerk- en klassieke organisatiekenmerken (Chisholm, 1992; Christensen, Andreas Danielsen, Laegreid \& Rykkja, 2016). De diversiteit aan initiatieven met een verschillende organisatiegraad biedt kansen, maar roept ook nieuwe vragen op. De acties via de online platforms ontlenen hun legitimiteit aan de specifieke, lokale kennis, maar ook zij ontsnappen niet aan de vraag voor wie en namens wie ze activiteiten ontplooien en beslissingen nemen.

Zo werd in de nasleep van de aardbevingen in Nepal duidelijk dat noch de internationale hulporganisaties, noch spontane initiatieven als Kathmandu Living Labs in staat waren om de meest kwetsbaren in de afgelegen, getroffen gebieden te bereiken (Mulder \& Boersma, 2017). Het platform Ready2Help bleek weliswaar in staat om in korte tijd veel vrijwilligers te mobiliseren, maar het is het Rode Kruis tot nog toe niet gelukt de expertise van de vrijwilligers in de pool optimaal te benutten (Schmidt, Wolbers, Ferguson \& Boersma, 2017). We constateerden dat het Rode Kruis burgers vooral inzette voor generieke taken zoals bedden opzetten, maar slechts in beperkte mate selecteerde op specifieke kennis en vaardigheden zoals medische expertise of talenkennis.

\section{Slotopmerkingen}

Tot op heden zoekt het openbaar bestuur naar middelen en maatregelen om het maatschappelijke sturingsmodel volop te benutten. De reflex blijft nog steeds om de chaos van een ramp of crisis te beheersen door controle te zoeken over de hulpverlening. Maar zowel in Nederland als in andere landen zien overheidsinstanties in dat slimme sturing door het openbaar bestuur tijdens een ramp of crisis nodig is, om de responsecapaciteit van spontane initiatieven uit de samenleving optimaal te benutten en de legitimiteit van het eigen optreden te vergroten. Burgers zijn steeds beter in staat gebruik te maken van online platforms om zich te organiseren in de nasleep van rampen en crises. Online platforms bieden gemeenschappen organisatiecapaciteit buiten de formele overheidskaders om. De overheid ziet zich door de kracht van deze spontane initiatieven, in een situatie waarin haar optreden juist sterk onder druk staat, gedwongen maatschappelijke initiatieven in rampensituaties serieus te nemen. Het benutten, en waar mogelijk activeren van de burgerinitiatieven tijdens crisissituaties, daagt de formele, hiërarchische structuren waarmee het openbaar bestuur verantwoordelijkheid kan nemen, uit.

Het ontwikkelen van het vermogen tot platformsturing is dan ook een flinke uitdaging. In de genoemde voorbeelden zien we een continuüm van sturingsarrangementen dat loopt van het ontwikkelen van een geheel nieuwe structuur voor het betrekken van burgers bij zelforganisatie, tot het gebruiken van een coördinatieplatform. Platform sturing is dan slimme sturing die de adaptieve capaciteit van de overheid vergroot doordat het de aansluiting bij spontane burgerinitiatieven 
vergemakkelijkt. Aan de ene kant gaat het daarbij om het gebruikmaken van de kracht van de initiatieven die in de samenleving zijn ontstaan (effectiviteit) en aan de andere kant gaat het om de responsiviteit van de overheid (legitimiteit). Coördinatie van de hulpverlening draait dan niet om het beheersen van lokale initiatieven, maar juist om het benutten en versterken van de kracht ervan.

De casussen laten zien dat niet alleen tijdens een crisissituatie, maar ook daarna gebruikgemaakt kan worden van de vernieuwing die burgers bieden. Enerzijds is de uitdaging voor het openbaar bestuur en formele instanties om relevante burgerinitiatieven tijdig te herkennen en hierop aan te sluiten. Dat vergt een slimme aanpak na een ramp of crisis en het vergroten van het adaptief vermogen teneinde aan te sluiten bij spontane initiatieven. Hulpverlenende instanties, inclusief die van de overheid zullen hun organisatie zodanig moeten inrichten dat ze internetplatforms optimaal kunnen benutten. Anderzijds kan het openbaar bestuur (bij)sturen, als blijkt dat gelijkheid en de toegankelijkheid van hulp voor alle getroffenen problematisch zijn. De platforms, en de partijen die daarin opereren, bieden de overheid nieuwe mogelijkheden voor sturing, waarbij haar verbindende rol centraal staat: het ondersteunen van slimme sturingsarrangementen om zo de maatschappelijke veerkracht optimaal te benutten.

\section{Literatuur}

Albris, K. (2018). The switchboard mechanism: How social media connected citizens during the 2013 floods in Dresden. Journal of Contingencies and Crisis Management, early view.

Boersma, F.K., Ferguson, J., Groenewegen, P., \& Wolbers, J. (2014). Beyond the myth of control: Toward network switching in disaster management. Hiltz, S.R., Pfaff, M.S., Plotnick, L. and Robinson, A.C. (Eds.), ISCRAM 2014 Conference Proceedings, Penn State University, 125-129.

Boersma, F.K., Kraiukhina, A., Larruina, R., Lehota, Z., \& Nury, E.O. (2018). A port in a storm: Spontaneous volunteering and grassroots movements in Amsterdam. A resilient approach to the (European) refugee crisis. Social Policy \& Administration, 1-15.

Bunce, S., Partridge, H., \& Davis, K. (2012). Exploring information experience using social media during the 2011 Queensland floods: a pilot study. The Australian Library Journal, 61(1), 34-45.

Chisholm, D. (1992). Coordination without hierarchy: Informal structures in multiorganizational systems. Berkeley and Los Angeles: University of California Press, .

Christensen, T., Andreas Danielsen, O.L.E., Laegreid, P., \& Rykkja, L.H. (2016). Comparing coordination structures for crisis management in six countries. Public Administration, 94(2), 316-332.

Dynes, R.R. (1994). Community emergency planning: False assumptions and inappropriate analogies. International Journal of Mass Emergencies and Disasters, 12(2), 141-158.

Helsloot, I., \& Ruitenberg, A. (2004). Citizen response to disasters: a survey of literature and some practical implications. Journal of Contingencies and Crisis Management, 12(3), 98-111.

Janssen, M., \& Estevez, E. (2013). Lean government and platform-based governance Doing more with less. Government Information Quarterly, 30, S1-S8. 
Kendra, J.M., \& Wachtendorf, T. (2016). American Dunkirk: The waterborne evacuation of Manhattan on 9/11. Philadelphia: Temple University Press.

Meijer, A.J. (2011). Networked coproduction of public services in virtual communities: From a government-centric to a community approach to public service support. Public Administration Review, 71(4), 598-607.

Meijer, A., Koops, B., Pieterson, W., Overman, S.P., \& Tije, S. (2012). Government 2.0: Key challenges to its realization. Electronic Journal of E-Government, 10(1), 59-69.

Mulder, F., \& Boersma, F.K. (2017). Linking up the last mile: How humanitarian power relations shape community e-resilience. Comes, T., Bénaben, T. Hanachi, C., Lauras, M. (eds.) ISCRAM 2017 Conference Proceedings, France: Albi, 715-725.

Mulder, F., Ferguson, J., Groenewegen, P., Boersma, F.K., \& Wolbers, J. (2016). Questioning Big Data: Crowdsourcing crisis data towards an inclusive humanitarian response. Big Data \& Society, 3(2), 1-13.

Ross, A. (2015). Parisians use \#PorteOuverte hashtag for those seeking safety from attacks. Time 13 November 2015 (http://time.com/4112428/paris-shootings-porteouverte/).

Schmidt, A., Wolbers J., Ferguson J., \& Boersma, F.K. (2017). Are you Ready2Help? Conceptualizing the management of online and onsite volunteer convergence. Journal of Contingencies and Crisis Management, 14 September 2017.

Slot, M.J., Cuppen, E., Doorn, N., Galeano Galvan, M., \& Klievink, A.J. (2017). Crowdbased innovaties: verschuivende verantwoordelijkheden in een institutional void. Bestuurskunde, 26(3), 31-42.

Smets, P., Younes, Y., Dohmen, M., Boersma, F.K., \& Brouwer, L.A. (2017). Sociale media in en rondom de vluchtelingen-noodopvang bij Nijmegen. Mens \& Maatschappij. Tijdschrift voor Sociale Wetenschappen, 92(4), 395-420.

Solnit, R. (2010). A paradise built in hell: The extraordinary communities that arise in disaster. New York: Viking.

Streep, A. (2015). Nepal's aid system is broken. So these lifesavers hacked it. Wired.

Tierney, K. (2014). The social roots of risk: Producing disasters, promoting resilience. Stanford: Stanford University Press.

Voorberg, W.H., Bekkers, V.J., \& Tummers, L.G. (2015). A systematic review of co-creation and co-production: Embarking on the social innovation journey. Public Management Review, 17(9), 1333-1357.

Wolbers, J., Ferguson, J., Groenewegen, P., Mulder, F., \& Boersma, F.K. (2016). Two faces of disaster response: Transcending the dichotomy of control and collaboration during the Nepal earthquake relief operation. International Journal of Mass Emergencies and Disasters, 34(4), 419-438.

Zook, M., Graham, M., Shelton, T., \& Gorman, S. (2010). Volunteered geographic information and crowdsourcing disaster relief: A case study of the Haitian earthquake. World Medical \& Health Policy, 2(2), 7-33. 